\title{
Gear Fault Detection with Time-Frequency Based Parameter NP4
}

\author{
V. V. POLYSHCHUK ${ }^{1, *}$, F. K. CHOY ${ }^{2}$, and M. J. BRAUN ${ }^{2}$ \\ ${ }^{1} B \& C$ Engineering Associates, Inc., 411 Wolf Ledges Parkway, Suite 104, Akron, Ohio 44311, USA, \\ ${ }^{2}$ Consultant, P.O. Box 2384, Akron, Ohio 44311, USA
}

The fact that the Wigner-Ville Distribution (WVD) can represent the energy of a gear vibration signal was used for the gear damage detection. A new gear fault detection parameter called NP4 is derived from the joint timefrequency Wigner-Ville Distribution. The novelty of the NP4 parameter is in application of the previously defined statistical parameter called kurtosis to the WVD data and its interpretation for gear fault detection. The important distinct feature of the fault detection parameter NP4 from other fault detection parameters, such as figures of merit, is that it does not compare a measured gear vibration signal with the ideal one. Thus, the parameter NP4 can work for the fault detection without a long recorded vibration history of the gear. New techniques for enhancing the information content of the WVD of the gear vibration signal and the reliability of the parameter NP4 are also described.

The utility of the gear fault detection parameter has been demonstrated using numerous gear vibration experiments. A correlation between the level of the gear tooth damage and the value of the gear fault detection parameter NP4 is demonstrated. The gear fault detection strategy based on the developed parameter NP4 is presented and investigated in the paper.

Keywords: Fault detection; Wigner-Ville distribution; Time-frequency analysis; Gears

Gear transmissions are widely used in today's rotating machinery. With the increasing demand for high performance, safety and lower maintenance costs of the machinery, the gear transmission health monitoring has become a significant area for research. The major effort in the gear diagnostics has been applied to the development

Received 30 March 2000; In final form 31 May 2000

*Corresponding author. Fax: (330)375-1627, e-mail: poly@bcea.com of the reliable methods for the fault detection of the gearboxes. However, current on-board condition monitoring systems for gear transmission systems often fail to provide sufficient time between warning and failure in order to implement the safety procedures. On the other hand, inaccurate interpretation of operational conditions may result in false alarms and unnecessary repairs and downtime.

One of the most promising procedures for detecting incipient faults in gears is the vibration/acoustic analysis. Vibration/acoustic analysis does not require a shutdown of the rotating machinery and it can be carried out by an online computer-based machine health monitoring system. Digital signal processing is usually applied to the vibration data to determine the gear conditions. Frequency spectrum analysis with FFT can be very effective tool in detecting the advanced gear faults. However, interpretation of the frequency spectrum may require the extensive past experience of the researcher or a maintenance engineer. A variety of gear fault indicators had been developed to facilitate the interpretation of the acquired gear vibration data and for use in the automated machine health monitoring systems. The examples of such gear fault indicators are FM0, FM4 (Zakrajsek et al., 1989, 1993), NA4 and NB4 (Zakrajsek et al., 1994; Decker et al., 1994). In the last decade, a joint time-frequency analysis with the Wigner-Ville Distribution (WVD) (Wang and McFadden, 1993; Choy et al., 1994) and the wavelet transforms (Wang and McFadden, 1996) had been applied to gear condition monitoring with the promise to deliver more accurate gear fault detection. As with the FFT analysis, these joint timefrequency distributions of the gear vibration signal could be difficult to interpret.

This paper presents a novel method for gear fault detection using new gear fault detection parameter NP4 (Polyshchuk et al., 2000) based on the joint time-frequency Wigner-Ville Distribution (WVD). The main result of this paper is the study of the NP4 performance during gear 
failure progression test. The novelty of the NP4 parameter is in the application of the previously defined statistical parameter, kurtosis, to the WVD data for gear fault detection. The usage of this gear fault detection parameter to gear tooth damage is demonstrated on a set of simulated signals and also applied to experimental results obtained from a gear fatigue test rig (Zakrajsek et al., 1994; Choy et al., 1994).

\section{INTRODUCTION OF THE FAULT DETECTION PARAMETER NP4}

In order to examine the sensitivity of the WVD to sudden changes in the signal, a parameter NP4 was defined as the normalized kurtosis of the signal power $P(t)$ as derived in the appendix

$$
\mathrm{NP} 4=\frac{1}{N} \sum_{i=1}^{N}\left(\frac{P\left(t_{i}\right)-\bar{P}}{\sigma}\right)^{4}-3
$$

where $\sigma$ is the standard deviation of $P(t)$ (Polyshchuk et al. (2000)). NP4 is a nondimensional parameter that depends only on the shape of the power distribution $P(t)$ and is invariant to scale transformation. The scale invariance property of this fault detection parameter can greatly simplify its applications and will be demonstrated in the following numerical examples.

Table I provides NP4 values for the signal presented in Figures 1-8.
As can be seen from the above table the NP4 had relatively large and positive values for signals with shortterm amplitude increase and phase change. The NP4 decreased when the signal power distribution widened (Figures 6-8). The results for the Figures 3, 4 and 8 deserve a special discussion. A signal power distribution in Figure 3 has a clearly defined small narrow peak located between two large wide peaks. The NP4 parameter senses the overall distribution as sharper than a normal distribution by turning positive. In the case shown in Figure 4 that the power signal distribution has many regularly appearing peaks. For NP4 parameter the overall distribution appears to be closer to a sine wave than to a normal distribution. NP4 parameter for Figure 8 is approximately half of

TABLE I Kurtosis and NP4 values for examples shown in Figures 1-8

\begin{tabular}{|c|c|c|c|}
\hline $\begin{array}{l}\text { Figure } \\
\text { number }\end{array}$ & Signal type & $\begin{array}{l}\text { Kurtosis of } \\
\text { the signal }\end{array}$ & NP4 values \\
\hline 1 & Sine wave & -1.50 & -1.35 \\
\hline 2 & Two sine waves & -0.74 & -0.93 \\
\hline 3 & $\begin{array}{l}\text { Short-term amplitude and } \\
\text { phase change }\end{array}$ & -1.45 & 0.25 \\
\hline 4 & $\begin{array}{l}\text { Short-term amplitude } \\
\text { decrease }\end{array}$ & -1.45 & -1.21 \\
\hline 5 & $\begin{array}{l}\text { Short-term amplitude } \\
\text { increase }\end{array}$ & -1.43 & 6.8 \\
\hline 6 & $\begin{array}{l}\text { Short-term phase change, } \\
3 \text { degrees }\end{array}$ & -1.50 & 5.83 \\
\hline 7 & $\begin{array}{l}\text { Short-term phase change, } \\
6 \text { degrees }\end{array}$ & -1.50 & 0.92 \\
\hline 8 & $\begin{array}{l}\text { Short-term phase change, } \\
24 \text { degrees }\end{array}$ & -1.50 & -0.73 \\
\hline
\end{tabular}
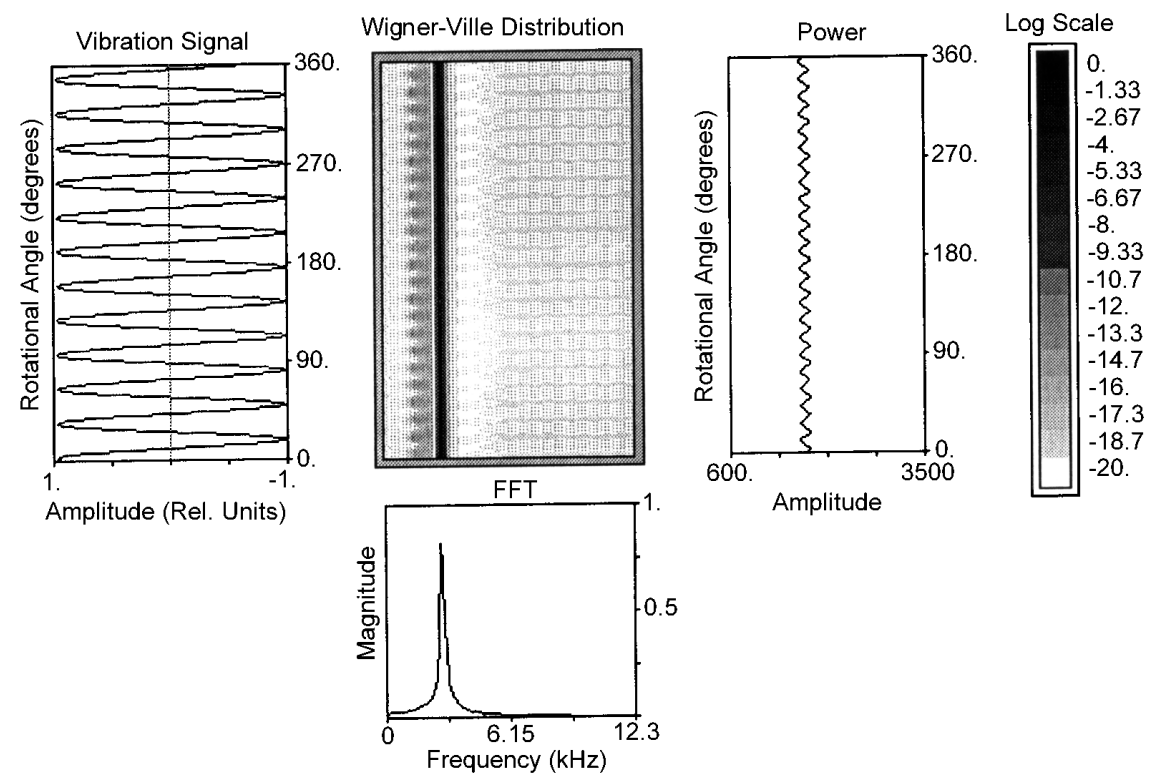

FIGURE 1 WVD of a sine wave time signal. 

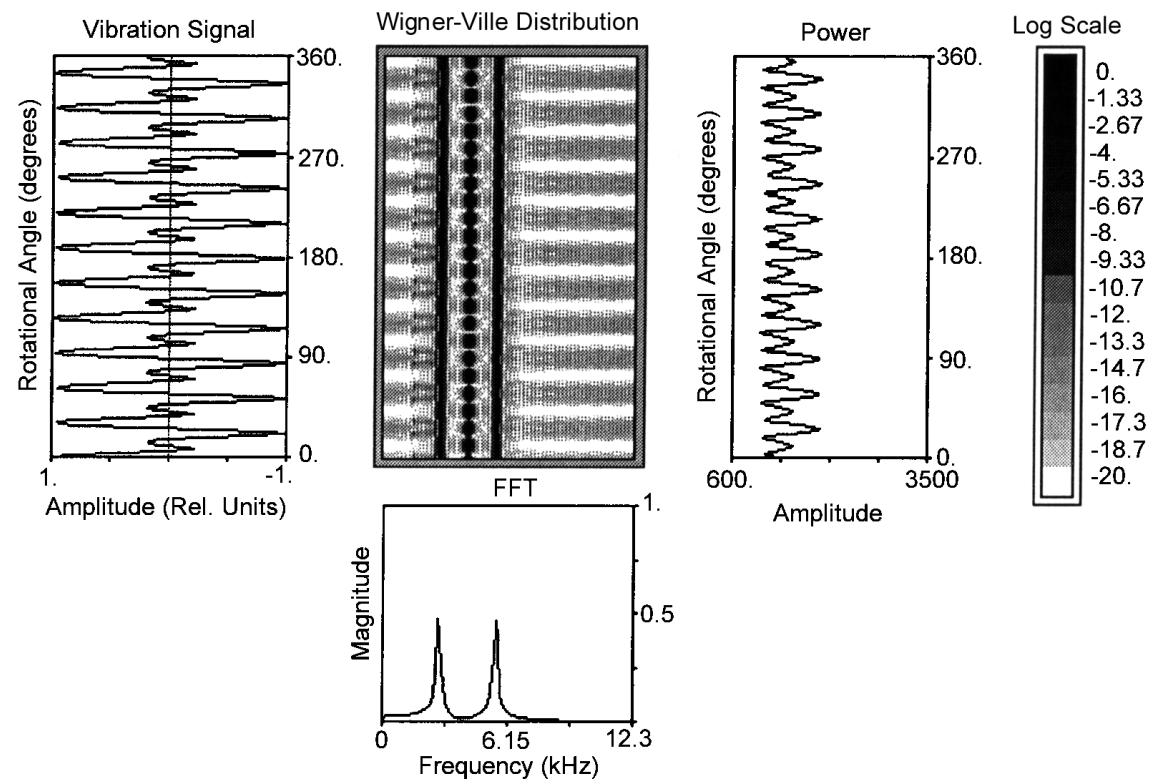

FIGURE 2 WVD of a time signal consisting of two sine waves.
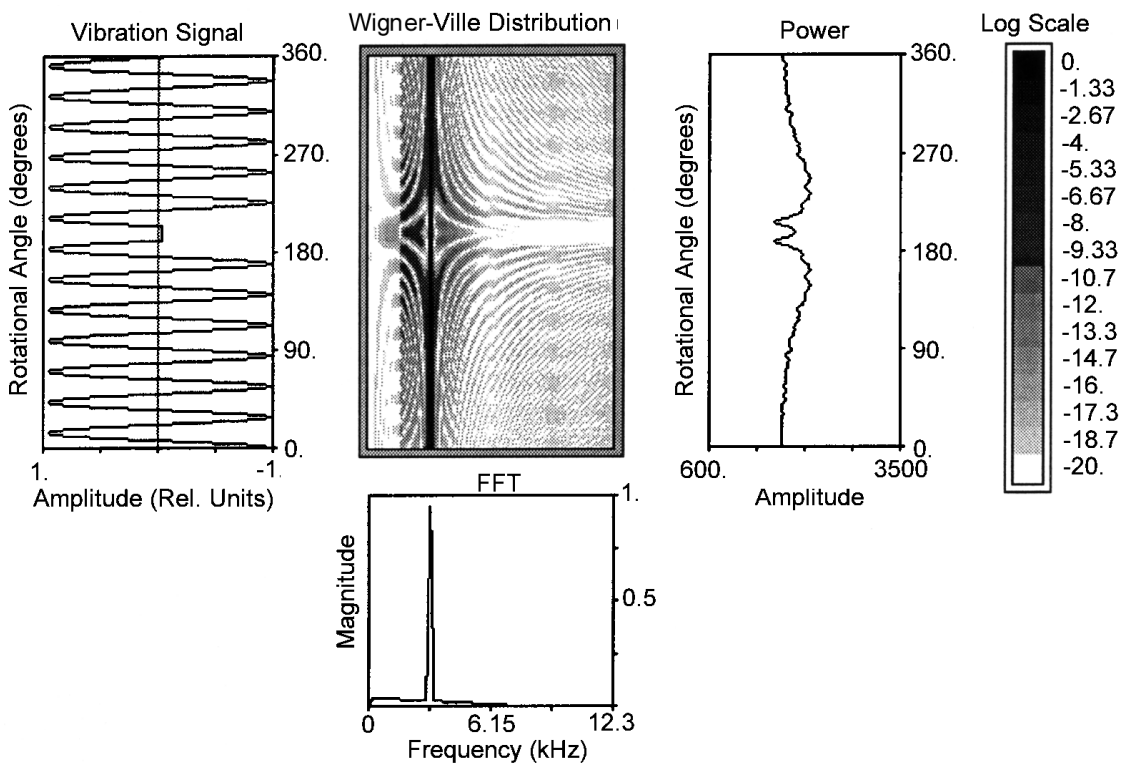

FIGURE 3 WVD of a time signal with short-term amplitude and phase change

the value for a kurtosis of a sine wave. It indicates that the signal power distribution is flatter than a normal distribution and there are fewer peaks in the distribution than in a sine wave. It was previously mentioned that a signal depicted in Figure 8 would be more likely indicative of consecutive gear teeth faults.

The detection capabilities of the NP4 parameter could be enhanced in a similar manner as for the NA4 parameter. Most of the rotating machinery components including gearboxes produce complex vibration signals. Some of these vibration components might indicate faulty conditions if they are viewed on the appropriate signal energy scale without being attenuated by the signal components with a higher energy content. A residual vibration signal can help to investigate a vibration signal on different energy scales. The residual vibration signal of order $N$ is constructed by filtering out the $N$ largest frequency components. For example, in order to construct the $N$-th 

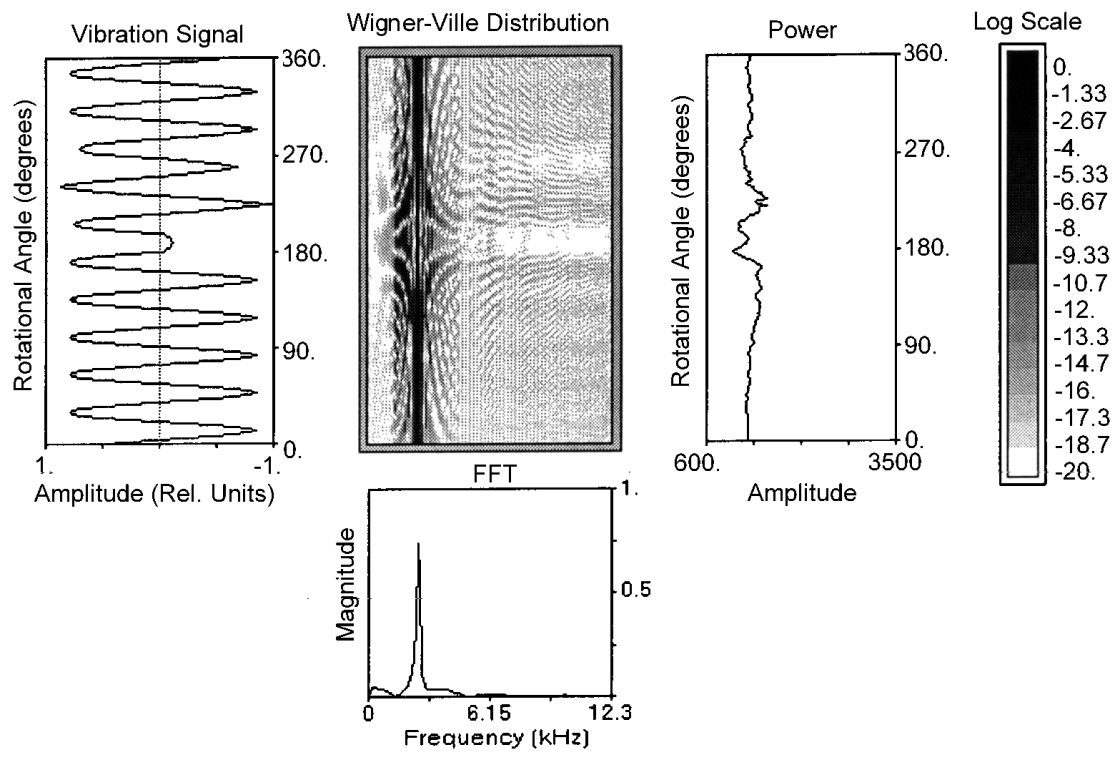

FIGURE 4 WVD of a time signal with short-term amplitude decrease.

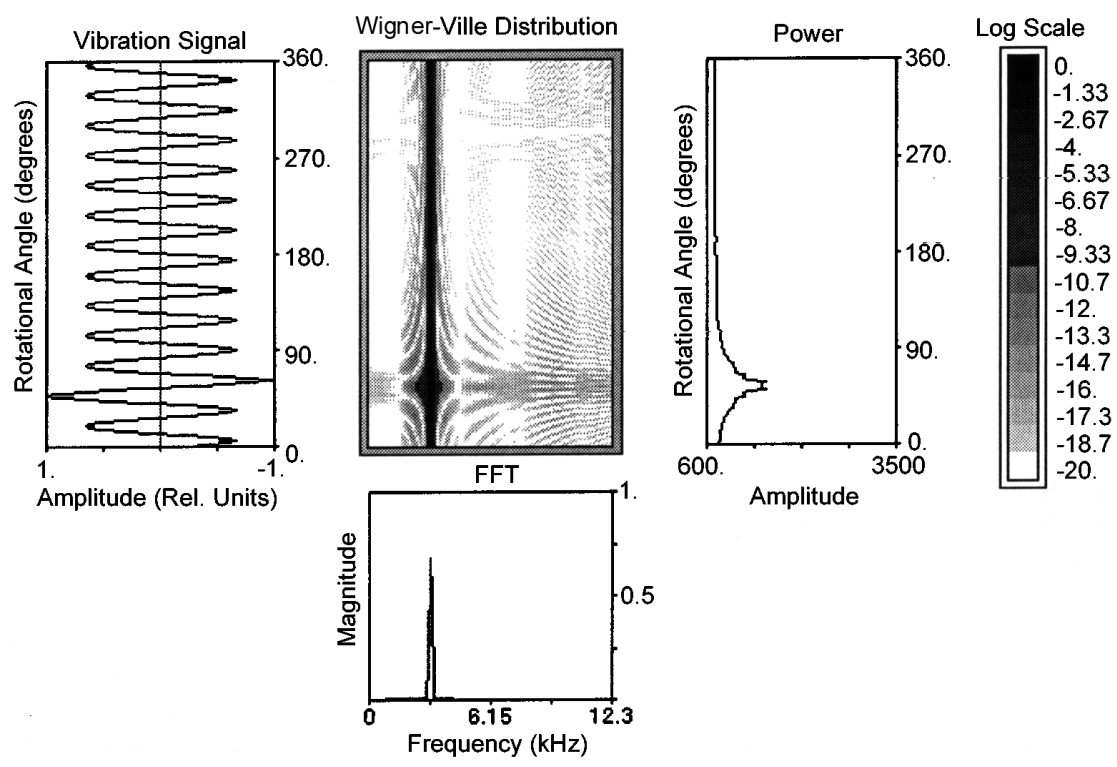

FIGURE 5 WVD of a time signal with short-term amplitude increase (burst).

order residual signal, the $N$-th order frequency component is removed from the signal giving a $N$-th order residual signal NP4 $(N)$.

\section{EVALUATION OF NP4 PERFORMANCE ON THE EXPERIMENTAL DATA}

The performance of NP4 was studied using the experimental data obtained from a gear fatigue test at the NASA
Glenn Research Center. Vibration data were obtained from accelerometers mounted on the pinion shaft bearing housing. The gearbox had two spiral bevel gears: a 12tooth pinion and a 36-tooth gear with 3.5 inch pitch diameter, 1 inch face width, 22.5 degree pressure angle, 90 degree shaft angle, and 35 degree spiral angle. The pinion transmitted $720 \mathrm{HP}$ at a speed of $14,400 \mathrm{RPM}$. The test rig was started and stopped several times for gear damage inspection. The test was ended after approximately 17 hours when a broken gear tooth was found during one of the shutdowns. A series of pictures showing the deterioration 


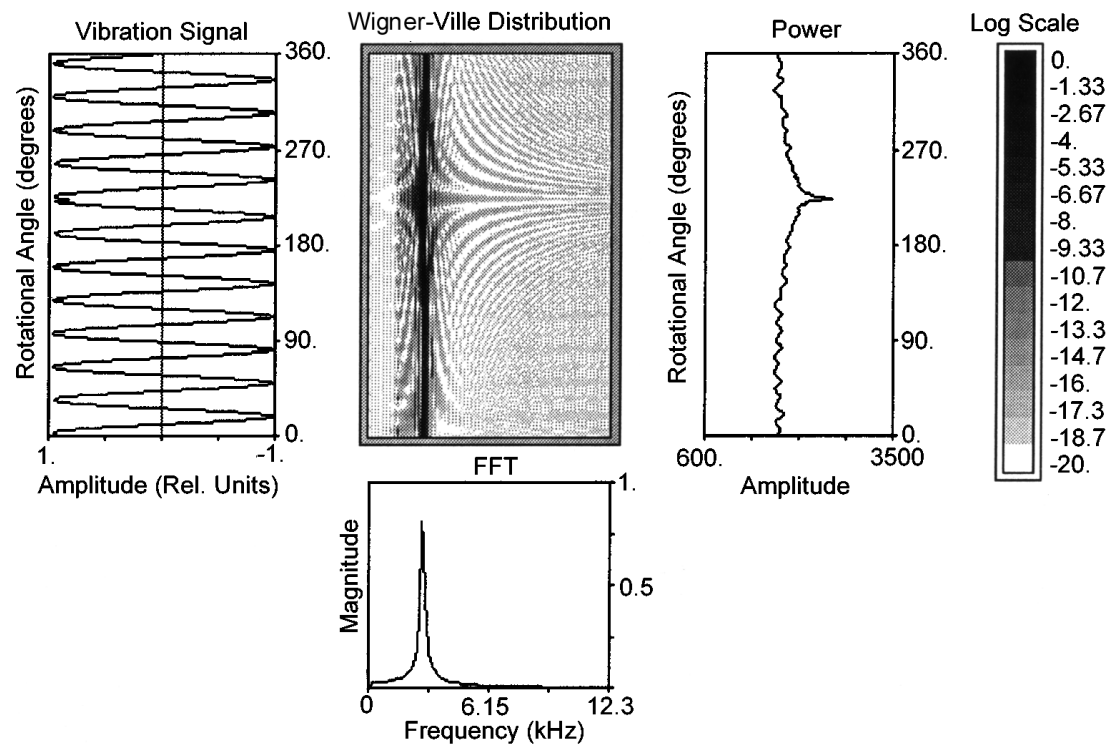

FIGURE 6 WVD of a time signal with 3 degrees phase change.

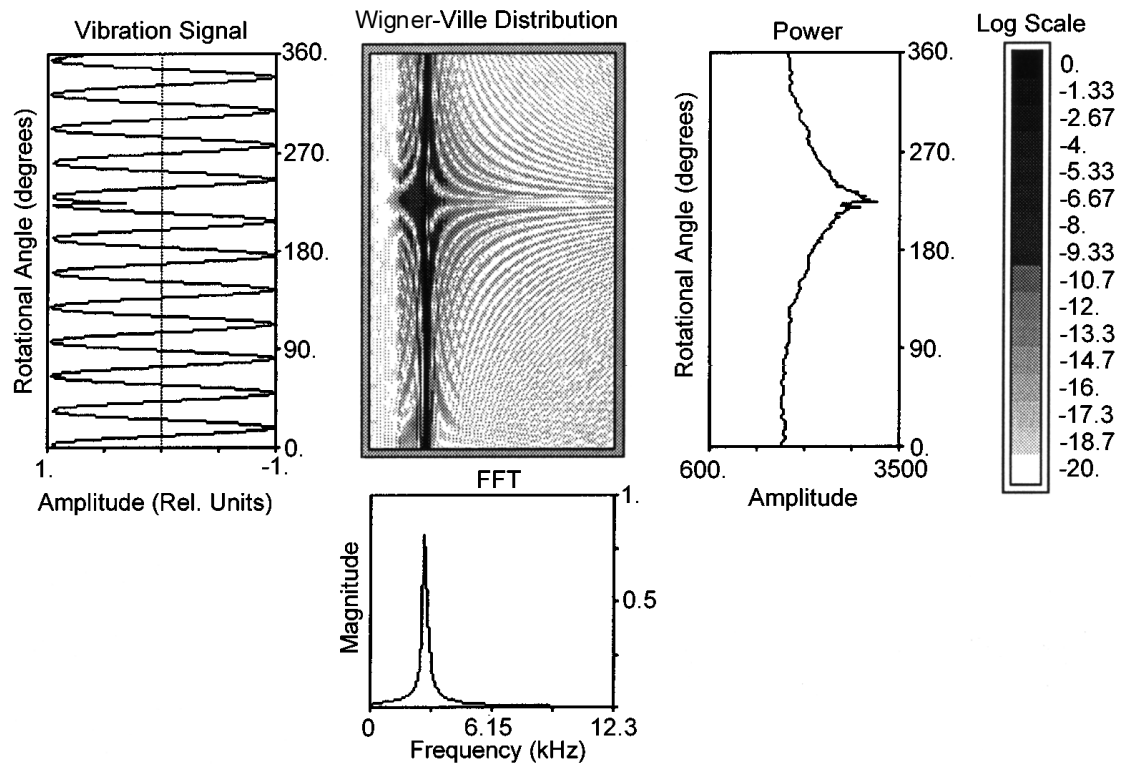

FIGURE 7 WVD of a time signal with 6 degrees phase change.

of the pinion teeth at various stages of the test are illustrated in Figures 9a and 9b.

In Figure 9a the initiation of a small pit on one of the pinion teeth during the first shutdown is shown at about 5.5 hours into the test. As the test progressed, the rig was shut down seven more times to examine the severity of the pitting. Figures $9 b$ and $9 c$ show the increase of the damaged area at the pinion tooth as the elapsed time increased to 8.55 , and 10.03 hours respectively. After
12.03 hours of testing, the damage of the pinion tooth increased to 75 percent of the tooth surface as shown in Figure 9d. Since then, pitting also initiated on the adjacent tooth and continued to grow as the time passed. At $16.16 \mathrm{hr}$, the damage has grown to three adjacent teeth as shown in Figure 9e. The test was stopped after 17.79 hours. It was observed that a portion of a gear tooth was broken on one of the heavily pitted teeth as shown in Figure 9f. 


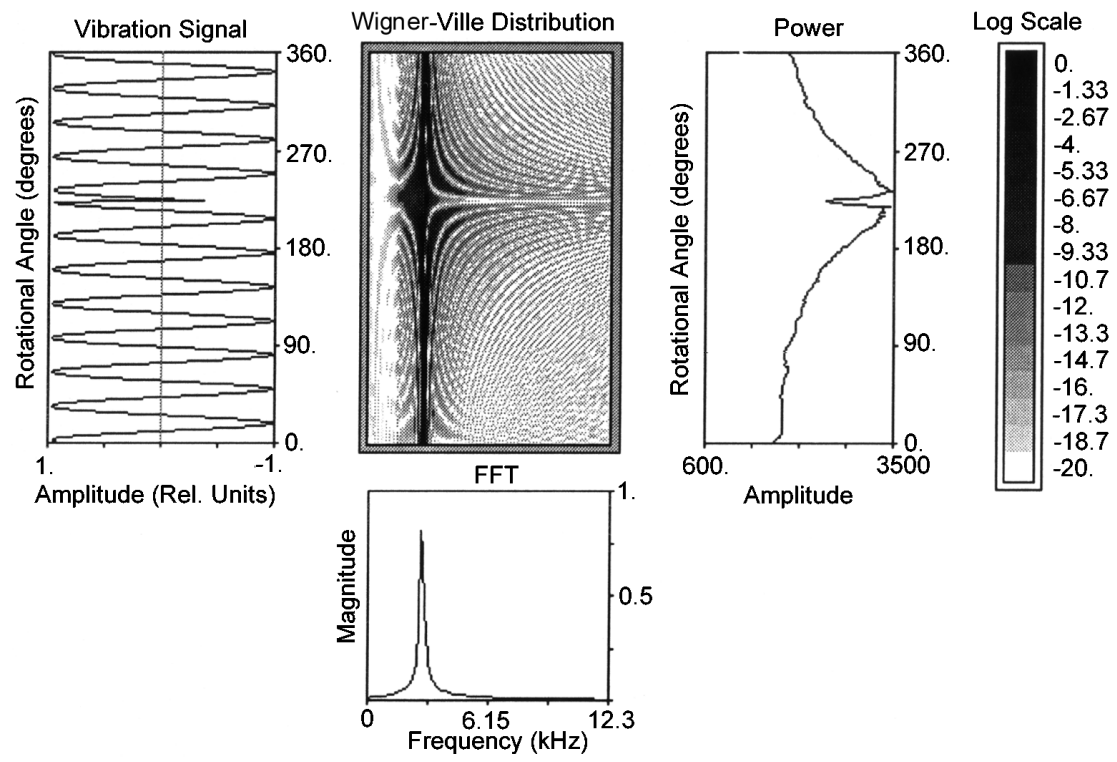

FIGURE 8 WVD of a time signal with 24 degrees phase change.

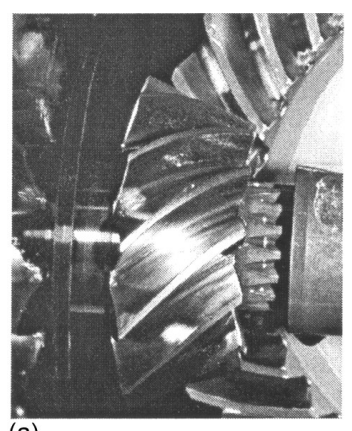

(a)

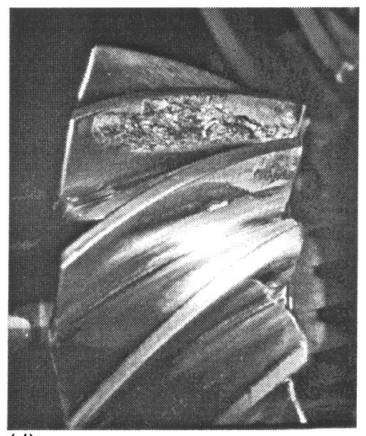

(d)

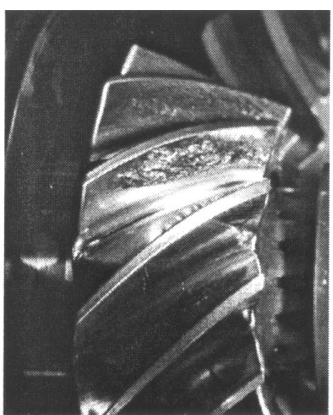

(b)

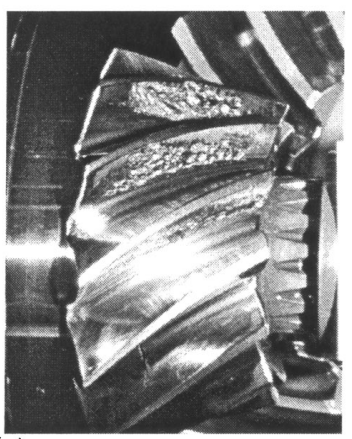

(e)

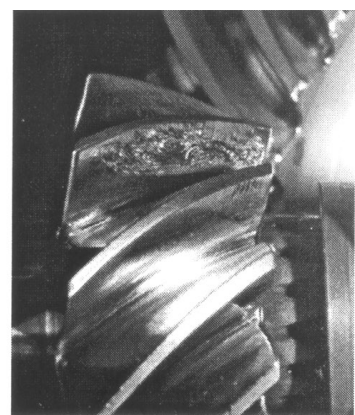

(c)

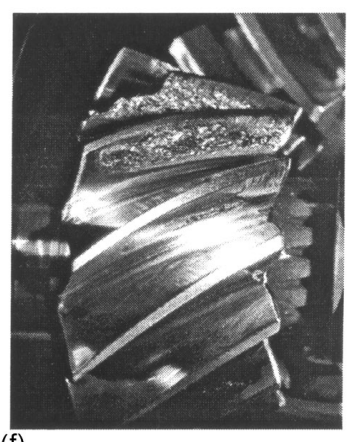

(f)

FIGURE 9 Photograph of pinion damage at (a) $5.50 \mathrm{hr}$; (b) $8.55 \mathrm{hr}$; (c) $10.03 \mathrm{hr}$; (d) $12.03 \mathrm{hr}$; (e) $16.16 \mathrm{hr}$; (f) $17.79 \mathrm{hr}$.

Figures $10-15$ present the results of the WVD for the spiral bevel gear vibration at various stages of damage as depicted in Figure 9. The gear vibration signatures for the various stages of damage were processed in the following manner. First, the WVD of the vibration signal was obtained and displayed. Then, a parameter NP4(0) was calculated for the signal power distribution. Secondly, the WVD for the 1-st order residual vibration signal was calculated as well as a corresponding parameter NP4(1). It was expected that NP4(1) would confirm the result of NP4(0) in the case of the single gear tooth damage. The parameters NP4(0) and NP4(1) for the various vibration 

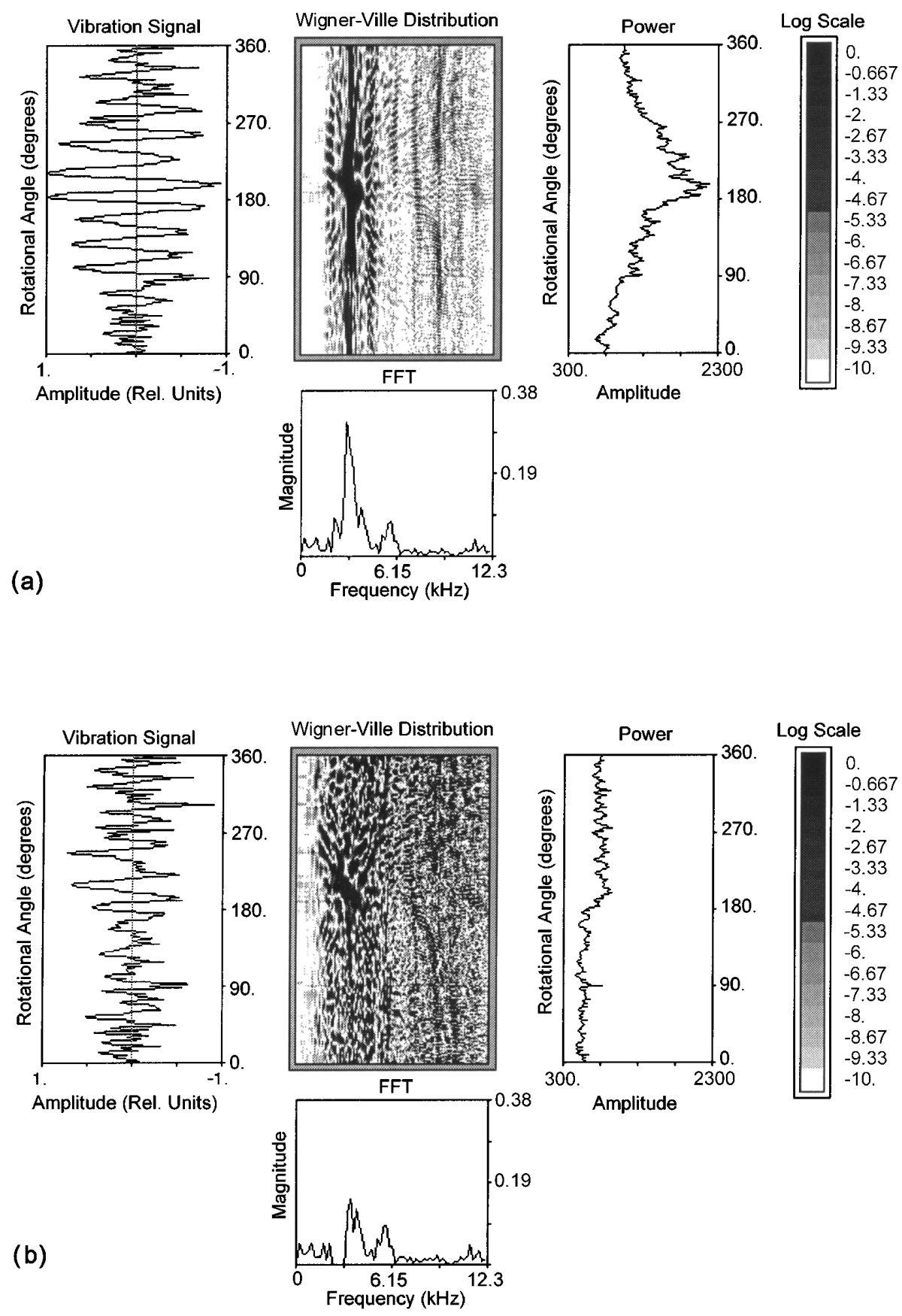

(b)

FIGURE 10 WVD of the gear vibration signal at $5.5 \mathrm{hr}$. (a) The original vibration signal; (b) The 1-st order residual gear vibration signal.

signals shown in Figures $10-15$ are shown in plotted in Figures 16a and 16b.

It should be noted that the gears were overloaded from the beginning of the experiment to accelerate the gear tooth wear. The WVD for the beginning of the experiment (see Figure 10a) displayed that the vibration energy was distributed between $135^{\circ}$ and $270^{\circ}$ of gear revolution around gear mesh frequency. The WVD in Figure 10b for the 1-st order residual gear vibration signal did not detect any large area of the vibration energy concentration. The parameter NP4 was negative in both cases as given in Table II are: $\mathrm{NP} 4(0)=-0.87$ and NP4(1) $=-0.46$. Figures $10 \mathrm{a}$ and $10 \mathrm{~b}$ show the build-up of the vibration power around $180^{\circ}$ of gear revolution at 5.5 hours. However, the peakedness of 

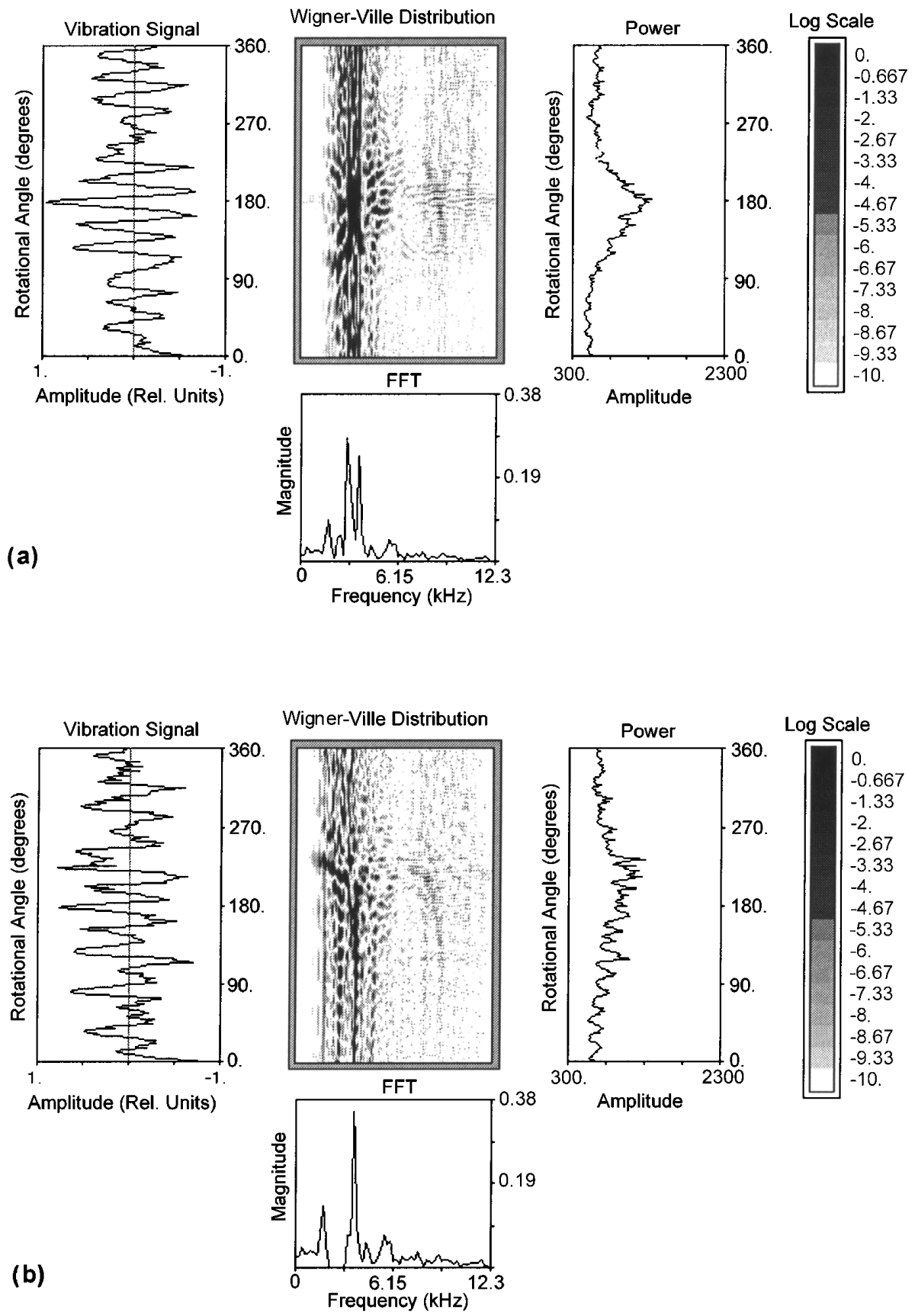

FIGURE 11 WVD of the gear vibration signal at $8.6 \mathrm{hr}$. (a) The original vibration signal; (b) The 1-st order residual gear vibration signal.

the signal power was not large enough to cause the parameters NP4(0) and NP4(1) become greater than zero and set the fault alarm. The parameter NP4 did not detect a single gear tooth damage until 6.55 hours after test startup. The single gear tooth fault was confirmed by both NP4(0) and NP4(1) parameters (see Table II). The parameter NP4(0) showed that the single gear tooth damage was increasing until 10.6 hours as shown in
Figure 12. The parameter NP4(1) confirmed the existence of the single gear tooth damage. After 10.6 hours into the experiment the parameter NP4(0) began decreasing, although kept being positive until 14.6 hours of the run time. This indicated that the gear tooth damage started to be more pronounced on the adjacent gear teeth. The last statement can be verified by comparing the Figures 9c for 10.03 hours and $9 \mathrm{~d}$ for 12.03 hours. The photographs 

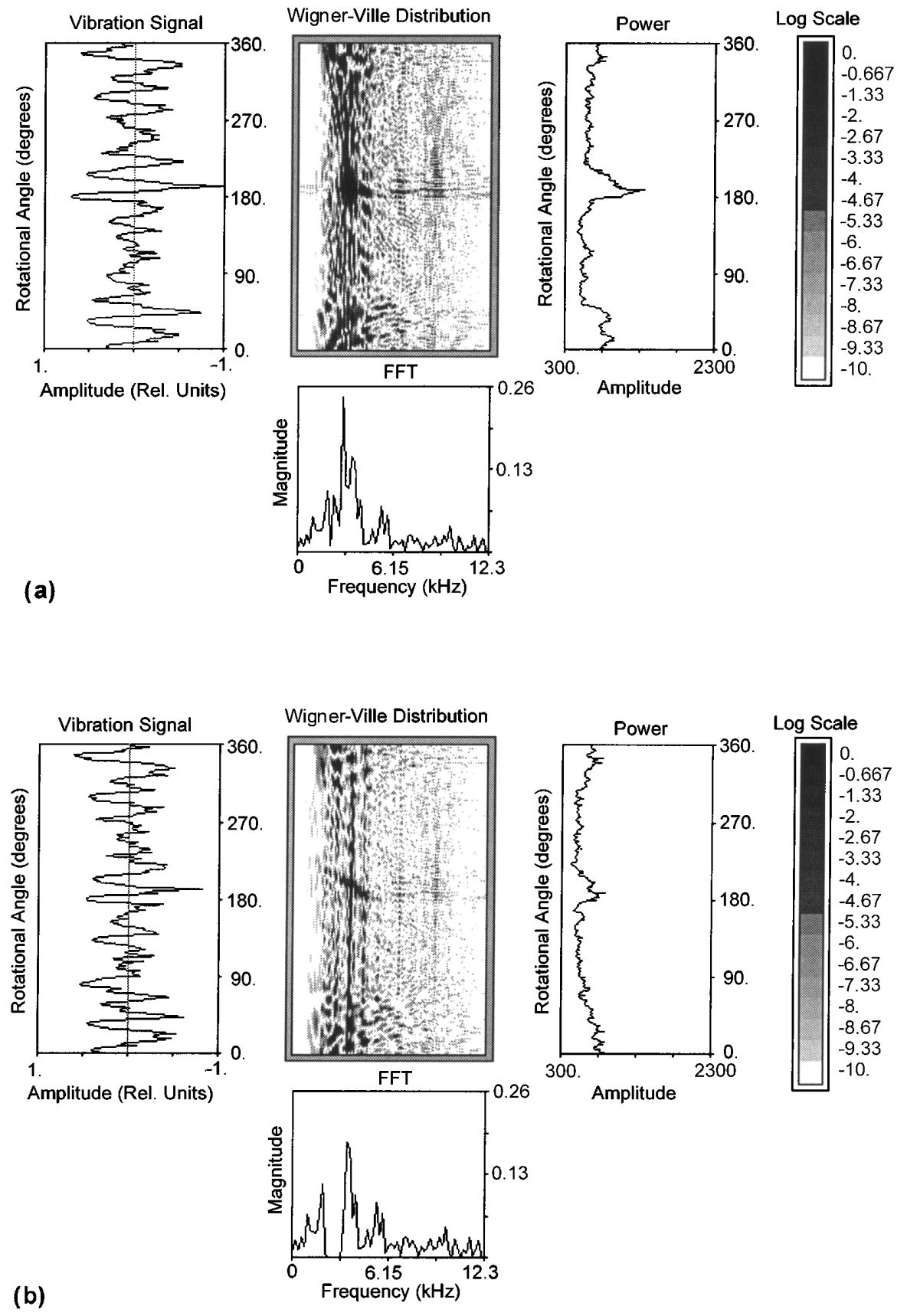

FIGURE 12 WVD of the gear vibration signal at $10.6 \mathrm{hr}$. (a) The original vibration signal; (b) The 1-st order residual gear vibration signal.

showed the increase in the adjacent gear teeth damage. The parameter NP4(1) was confirming the results of NP4(0) until 10.03 hours of run time. One may conclude that the parameters NP4(0) and NP4(1) both detected and confirmed the single gear tooth damage at any time point between 6.55 and 10.03 hours of run time. Between 12.1 and 14.6 hours the parameter NP4(0) was positive, which signaled the gear tooth damage conditions. The parameter
NP4(1) was negative at that time interval. The WVD in Figure 13b provides some explanations for NP4(1) detection failure. The WVD of the residual signal contained the energy signatures for the damage initiation on the adjacent gear teeth spread between $90^{\circ}$ and $200^{\circ}$ of gear revolution. As a result, the signal power distribution was flat. The conditions between 12.1 and 14.6 hours could be described as $\mathrm{NP}(0)>0$ and $\mathrm{NP} 4(1)<0$, which should 


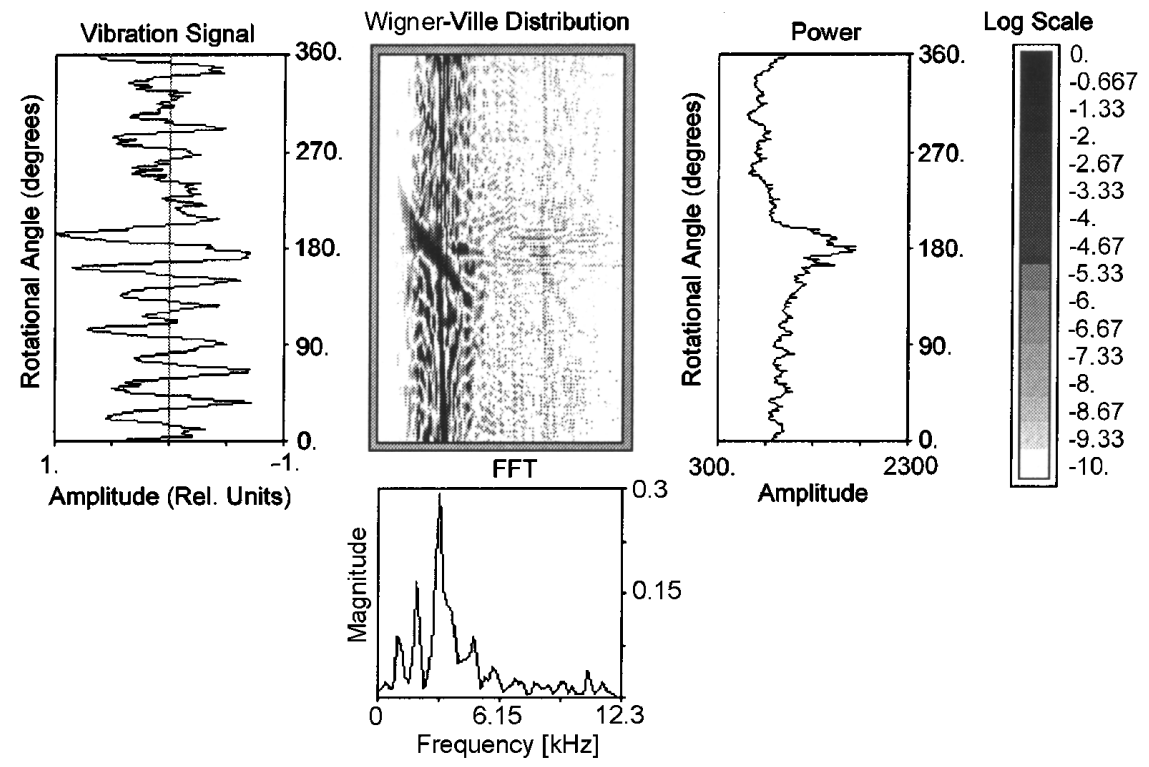

(a)

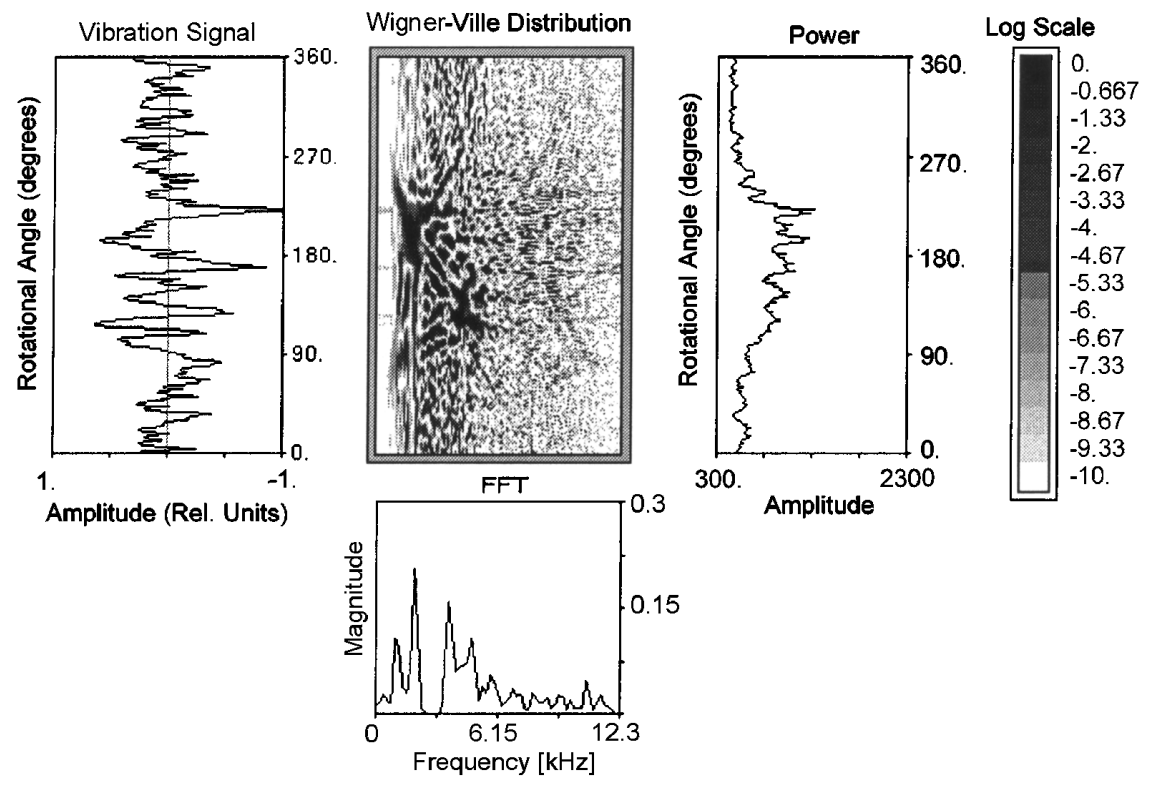

(b)

FIGURE 13 WVD of the gear vibration signal at $12.1 \mathrm{hr}$. (a) The original vibration signal; (b) The 1-st order residual gear vibration signal.

indicate possible multiple gear tooth damage. The signal power distribution and the WVD indicate that the gear tooth damage spread to other gear teeth. The parameter NP4(0) was negative. The parameter NP4(1) detects it by taking a positive value as shown in Table II. The signal power distribution for WVD in Figure 16 at 16.2 hours clearly shows three distinct spikes corresponding to $90^{\circ}$, $135^{\circ}$ and $180^{\circ}$ of gear revolution. These power spikes could correspond to the damage on three gear teeth shown in Figure 2. $10 \mathrm{~g}$ at 16.16 hours of run time. Consequently, the 


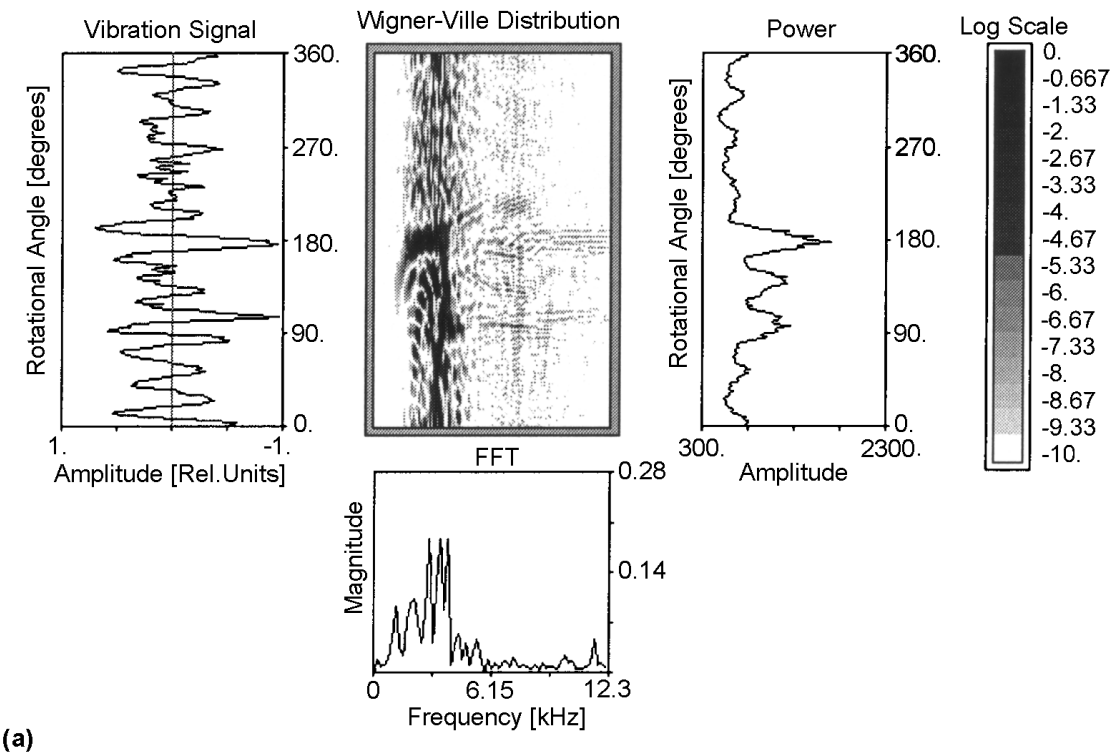

(a)

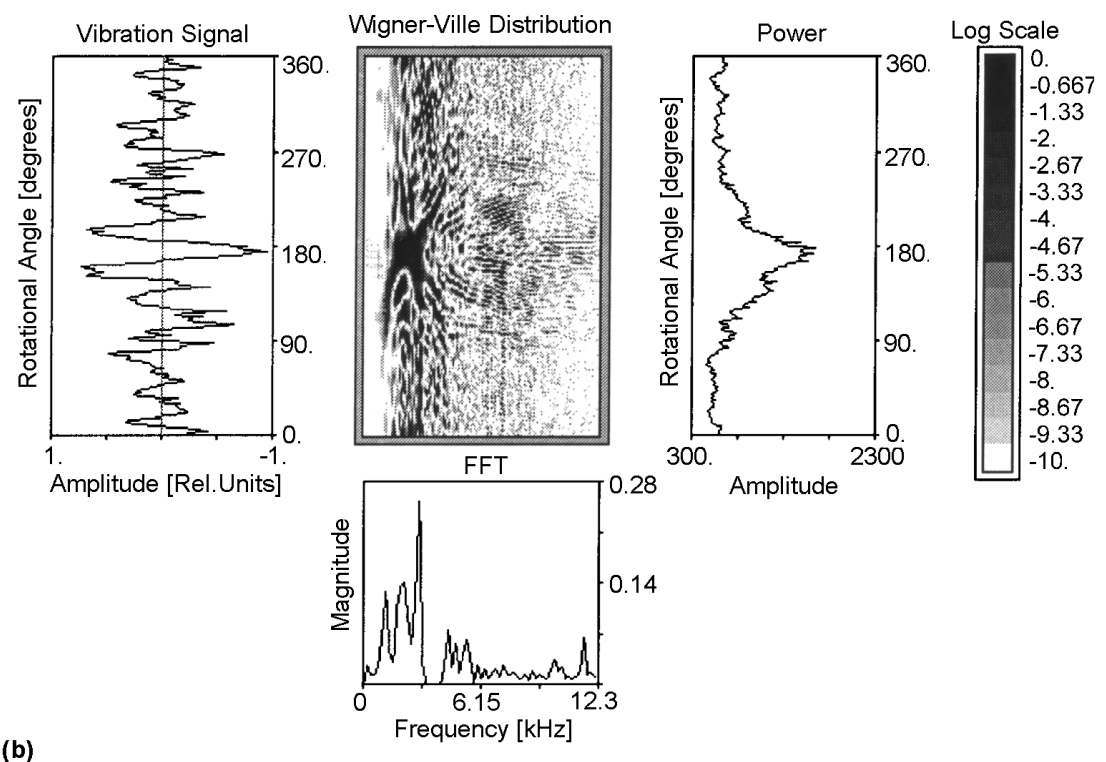

FIGURE 14 WVD of the gear vibration signal at $16.2 \mathrm{hr}$. (a) The original vibration signal; (b) The 1-st order residual gear vibration signal.

parameter NP4(0) failed at 16.20 hours of run time. Nevertheless, the parameter NP4(1) detected the damage conditions at $180^{\circ}$ of gear revolution after the frequencies associated with excitation from other damaged gear teeth were removed.

At the end of the test the multiple gear teeth were damaged as shown at the photograph of the gear at 17.79 hours in Figure 9f. The WVD in Figure 15 showed that the vibration energy was dispersed to multiple frequencies around the gearmesh frequency at 17.7 hours into the test. The parameters NP4(0) and NP4(1) were both negative. Thus, the fault detection parameter NP4 did not provide the indication of the multiple gear teeth damage.

The results shown in Table II demonstrate that the NP4based fault detection strategy performs well in case of a single gear tooth damage ("Fault $A$ " in Table II). In this table "Fault $A$ " indicates a single gear tooth damage confirmed by both NP4(0)>0 and NP4(1) $>0$. "Fault $B$ " 


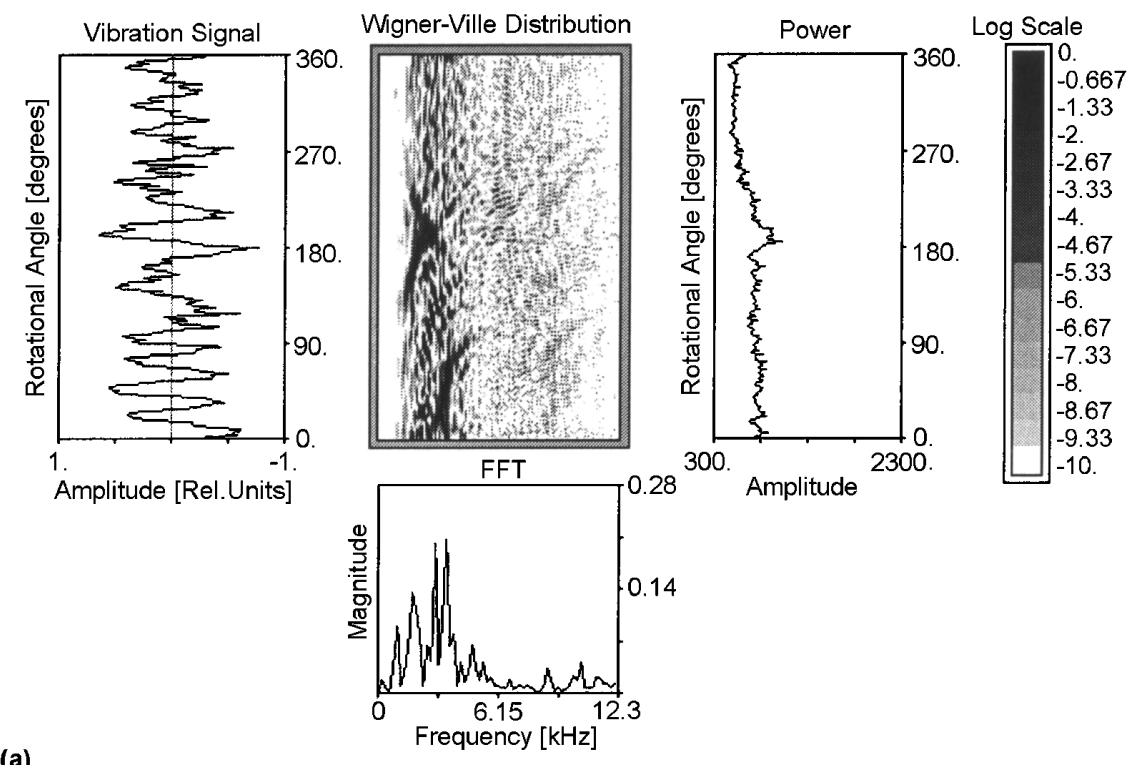

(a)

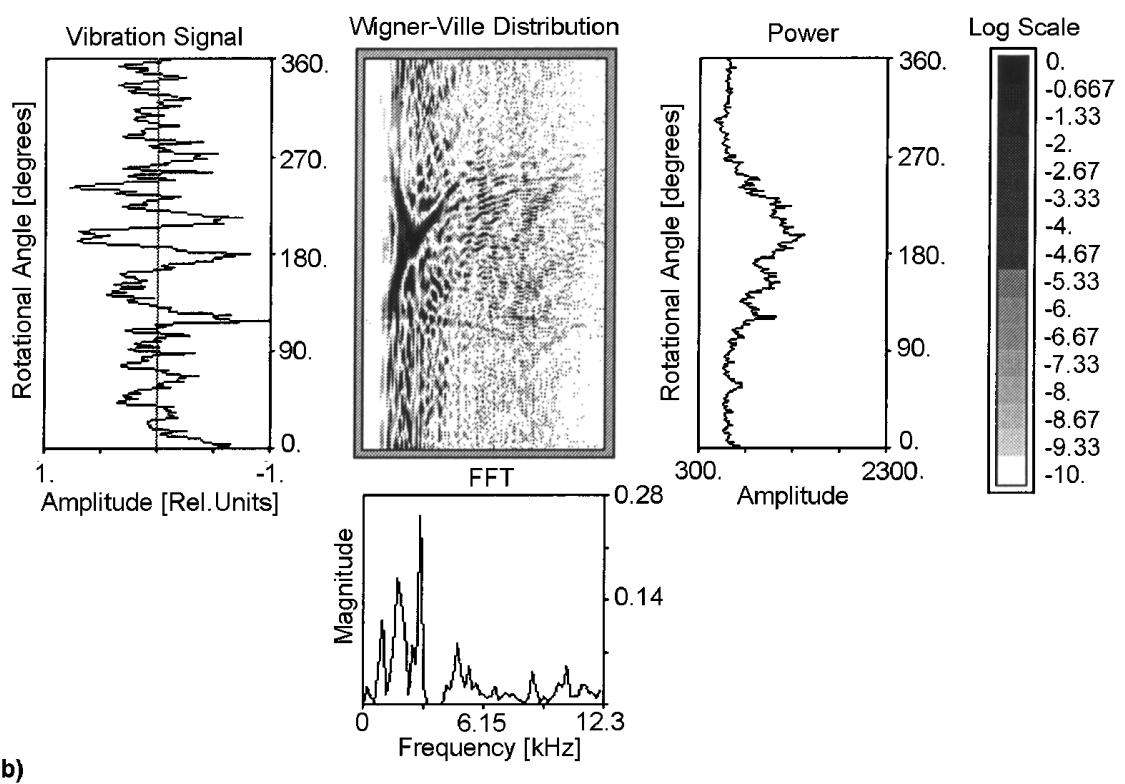

FIGURE 15 WVD of the gear vibration signal at $17.7 \mathrm{hr}$. (a) The original vibration signal; (b) The 1-st order residual gear vibration signal.

indicates a single gear tooth damage or a fault alarm set by conditions NP4(0) $>0$ and NP4(1) $<0$. "Fault $C$ " indicates possible multiple gear teeth damage or a fault alarm set by condition $\mathrm{NP} 4(0)<0$ and $\mathrm{NP} 4(1)>0$. The proposed strategy also was capable of detecting multiple gear teeth damages with exception of the last experiment number 15 . The analysis of the WVD for the experiment number 15 (Figures 15a and 15b) shows a large energy cluster spread around $180^{\circ}$ of gear revolution and close to the gearmesh frequency. Due to the size of the energy cluster the vibration signal power distribution does not have a sharp peak around $180^{\circ}$ of gear revolution, which results in poor performance of the parameter NP4. The parameter NP4(0) in Figure 16 was increasing with the progression of a single gear tooth damage until 11.2 hours into the experiment. The spread of the damage to adjacent gear teeth caused the parameter NP4(0) to trend down from 11.2 to 14.6 hours. Both plots for NP4(0) and NP4(1) depict a short-term increase in value between 14.6 and 17.7 hours. Most likely that for short period of time the damage on a single gear tooth accelerated and became more pronounced relatively to the adjacent gear teeth. 
TABLE II Fault detection results using NP4(0) and NP4(1)

\begin{tabular}{|c|c|c|c|c|c|}
\hline $\begin{array}{l}\text { Experiment } \\
\text { number }\end{array}$ & $\begin{array}{c}\text { Time, } \\
\text { hrs }\end{array}$ & NP4(0) & NP4(1) & $\begin{array}{c}\text { Detection } \\
\text { outcome }\end{array}$ & Observed gear conditions \\
\hline 1 & 0.0 & -0.87 & -0.46 & No fault & No fault \\
\hline 2 & 3.0 & -1.20 & -0.89 & No fault & No fault \\
\hline 3 & 5.5 & -0.42 & -1.34 & No fault & Small gear tooth pitting \\
\hline 4 & 5.6 & -1.34 & -0.88 & No fault & Small gear tooth pitting \\
\hline 5 & 6.55 & 0.97 & 1.86 & Fault $A$ & Single gear tooth damage \\
\hline 6 & 8.6 & 0.58 & 0.17 & Fault $A$ & Single gear tooth damage \\
\hline 7 & 9.33 & 0.70 & 4.45 & Fault $A$ & Single gear tooth damage \\
\hline 8 & 10.6 & 2.30 & 0.42 & Fault $A$ & Single gear tooth damage \\
\hline 9 & 11.6 & 1.80 & 1.29 & Fault $A$ & Single gear tooth damage \\
\hline 10 & 12.1 & 1.68 & -0.53 & Fault $B$ & $\begin{array}{l}\text { Single gear tooth damage and } \\
\text { pitting on the adjacent tooth }\end{array}$ \\
\hline 11 & 14.6 & 0.28 & -0.65 & Fault $B$ & $\begin{array}{l}\text { Single gear tooth damage and } \\
\text { pitting on the adjacent tooth }\end{array}$ \\
\hline 12 & 15.6 & -0.75 & 1.52 & Fault $C$ & $\begin{array}{l}\text { Single gear tooth damage and } \\
\text { pitting on two adjacent teeth }\end{array}$ \\
\hline 13 & 16.2 & 1.61 & 1.29 & Fault $B$ & $\begin{array}{l}\text { Single gear tooth damage and } \\
\text { pitting on two adjacent teeth }\end{array}$ \\
\hline 14 & 17.2 & -0.72 & 0.27 & Fault $C$ & $\begin{array}{l}\text { Single gear tooth damage and } \\
\text { pitting on two adjacent teeth }\end{array}$ \\
\hline 15 & 17.7 & -0.86 & -0.39 & No fault & $\begin{array}{l}\text { Single gear tooth fracture and } \\
\text { pitting on two adjacent teeth } \\
\text { Serious multiple gear tooth } \\
\text { faults }\end{array}$ \\
\hline
\end{tabular}

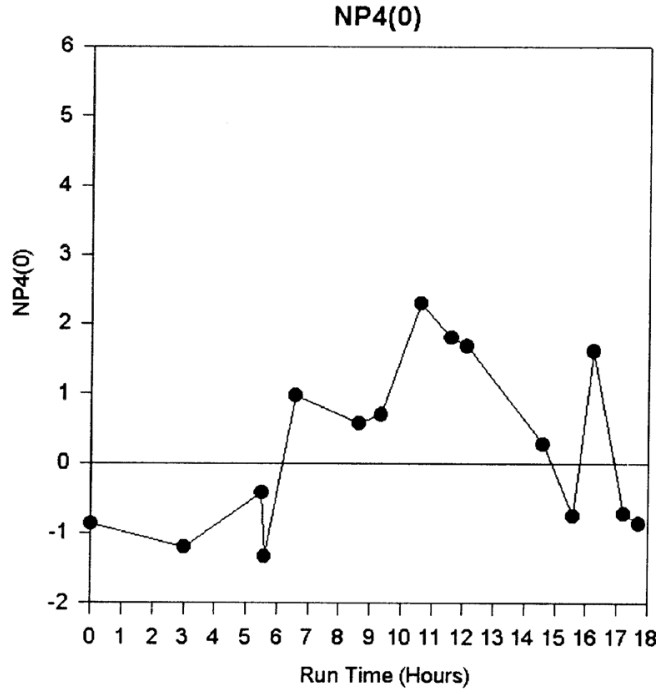

(a)

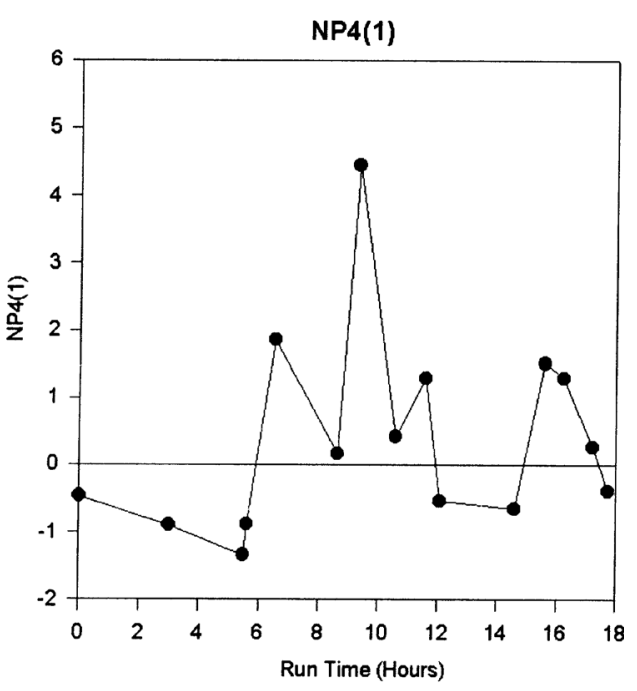

(b)

FIGURE 16 Fault detection parameter NP4 at various run times. (a) The original vibration signal; (b) The 1-st order residual gear vibration signal.

\section{CONCLUSIONS}

This paper presents the development of a novel method in gear damage detection using a new gear fault detection parameter based on the energy change in the joint timefrequency analysis of the vibration signals. The main accomplishment of this paper is the introduction of the gear fault detection parameter NP4, which is calculated from the time-domain power signal derived from the Wigner-Ville Distribution (WVD). Applying the developed NP4 parameter on a series of experimental data obtained from a NASA gear test rig has been successful in 
demonstrating the application of the NP4 parameter in detecting gear tooth damage. The following specific conclusions can be drawn from this experimental study:

1. The experiments demonstrated successfully the capability of the fault detection parameter NP4 to indicate a single gear tooth damage.

2. The performance of the fault detection parameter NP4 deteriorates as the severity of the damage increases on the multiple gear teeth.

3. Setting the threshold for NP4(0) to 0.1 does not change the fault detection results presented in the Table II. That is, the condition $\mathrm{NP}(0)>0.1$ and $\mathrm{NP} 4(1)>0.1$ can reduce possible false alarms.

4. The gear fault detection with parameter NP4 does not require the comparison of the undamaged (baseline) gear vibration signal with the acquired gear vibration signal.

5. The parameter NP4 avoids the necessity to interpret the time-frequency distributions such as the Wigner-Ville Distribution or Wavelet Transform for the gear fault detection.

\section{APPENDIX}

The Wigner-Ville Distribution (WVD) provides a timefrequency representation of the signal. It can be written as (Boashash, 1987)

$$
W_{x x}(t, f)=\int_{-\infty}^{\infty} x\left(t+\frac{\tau}{2}\right) x^{*}\left(t-\frac{\tau}{2}\right) \mathrm{e}^{-j 2 \pi f \tau} d \tau
$$

where $W_{x x}(t, f)$ is the Wigner-Ville Distribution of a complex continuous time analytic signal $x(t), t$ is a time variable and $f$ is a frequency variable. An important signal characteristics that can be defined from the WVD is the instantaneous energy of the signal, or signal power

$$
P(t)=\int\left|W_{x x}(t, f)\right| d f
$$

When a single gear tooth develops a significant defect, a peak appears in the vibration signal. A 4th order statistical parameter called kurtosis is used to detect the presence of a major peak in the vibration signal. The normalized kurtosis for a distribution $y(t)$ given by its $N$ values $y_{1}, \ldots, y_{N}$ measured at times $t_{1}, \ldots, t_{N}$ can be defined as

$$
N K(y(t))=\frac{1}{N} \sum_{i=1}^{N}\left(\frac{y_{i}-\bar{y}}{\sigma}\right)^{4}-3
$$

where $\bar{y}$ is a mean value, and $\sigma$ is the standard deviation of $y(t)$. Kurtosis is a nondimensional quantity. It is positive for a distribution consisting of a sharp single peak and is increasing with an increase in peakedness of a distribution. This property of the kurtosis is employed in construction of the gear fault detection parameter NP4, which is computed as the normalized kurtosis for the instantaneous signal power $P(t)$.

\section{REFERENCES}

Boashash, B. and Black, P. J. (1987) An Efficient Real Time Implementation of the Wigner-Ville Distribution, IEEE Transactions on Acoustics, Speech, and Signal Processing, ASSP-35(11), 1611-1618.

Choy, F. K., Huang, S., Zakrajsek, J. J., Handschuh, R. F. and Townsend, D. P. (1994) Vibration Signature Analysis of a Faulted Gear Transmission System, AIAA-94-2937, Paper Presented at the 30th AIAA Joint Propulsion Conference, Indianapolis, Indiana.

Choy, F. K., Braun, M. J., Polyshchuk, V., Zakrajsek, J. J., Handschuh, R. F. and Townsend, D. P. (1994) Analytical and Experimental Vibration Analysis of a Faulty Gear System, In: The 1994 AGMA Fall Technical Meeting, St. Louis, Missouri.

Choy, F. K., Polyshchuk, V., Zakrajsek, J. J., Handschuh, R. F. and Townsend, D. P. (1996) Analysis of the Effects of Surface Pitting and Wear on the Vibrations of a Gear Transmission System, Tribology International, 29(1), 77-83.

Choy, F. K., Xu, A. and Polyshchuk, V. V. (1998) Development of a Model-based Technique for Gear Diagnostics using Wigner-Ville Method, NASA Final Report on NASA Project NAG 3-1376.

Decker, H. J., Handschuh, R. F. and Zakrajsek, J. J. (1994) An Enhancement to the NAU Gear Vibration Diagnostic Parameter, NASA TM-106553, Presented at the 18th Annual Meeting of the Vibration Institute, Hershey, PA.

McFadden, P. D. and Smith, J. D. (1985) A Signal Processing Technique for Detecting Local Defects in Gear from the Signal Average of the Vibration, Proceedings of Institute of Mechanical Engineers, 199(C4), $287-292$.

Polyshchuk, V., Choy, F. K. and Braun, M. J. (2000) New Gear-FaultDetection parameter by Use of Joint Time-Frequency Distribution, AIAA Journal of Propulsion and Power, 16(2), 340-346.

Wang, W. J. and McFadden, P. D. (1993) Early Detection of Gear Failure by Vibration Analysis - I. Calculation of the Time-Frequency Distribution, and Early Detection of Gear Failure by Vibration Analysis II. Interpretation of the Time-Frequency Distribution Using Image Processing Techniques, Mechanical Systems and Signal Processing, 7(3), $193-203$, and $205-215$.

Wang, W. J. and McFadden, P. D. (1996) Application of Wavelets to Gearbox Vibration Signals for Fault Detection, Journal of Sound and Vibration, 192(5), 927-939.

Zakrajsek, J. J. (1989) An Investigation of Gear Mesh Failure Prediction Techniques, NASA Technical Memorandum 102340 and AVSCOM Technical Memorandum 89-C-005.

Zakrajsek, J. J., Towsend, D. P. and Decker, H. J. (1993) An Analysis of Gear Fault Detection Methods as Applied to Pitting Fatigue Failure Data, NASA TM-105950, Presented at the 47th Mechanical Failure Prevention Group Meeting, Virginia Beach, Virginia.

Zakrajsek, J. J., Handschuh, R. F. and Decker, H. J. (1994) Application of Fault Detection Techniques to Spiral Bevel Gear Fatigue Data, NASA TM-106467, Presented at the 48th Mechanical Failures Prevention Group Meeting, Wakefield, Massachusetts. 

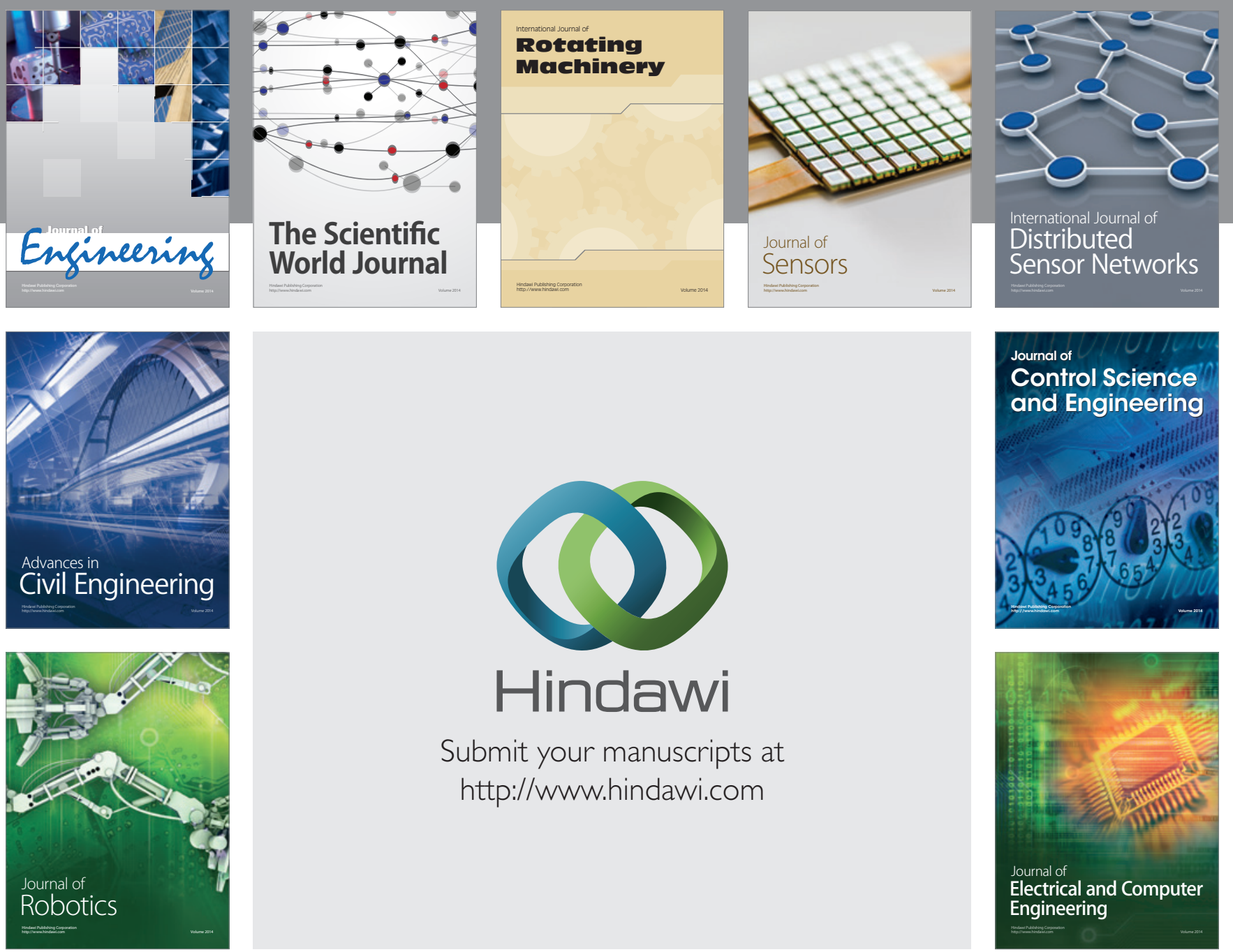

Submit your manuscripts at

http://www.hindawi.com
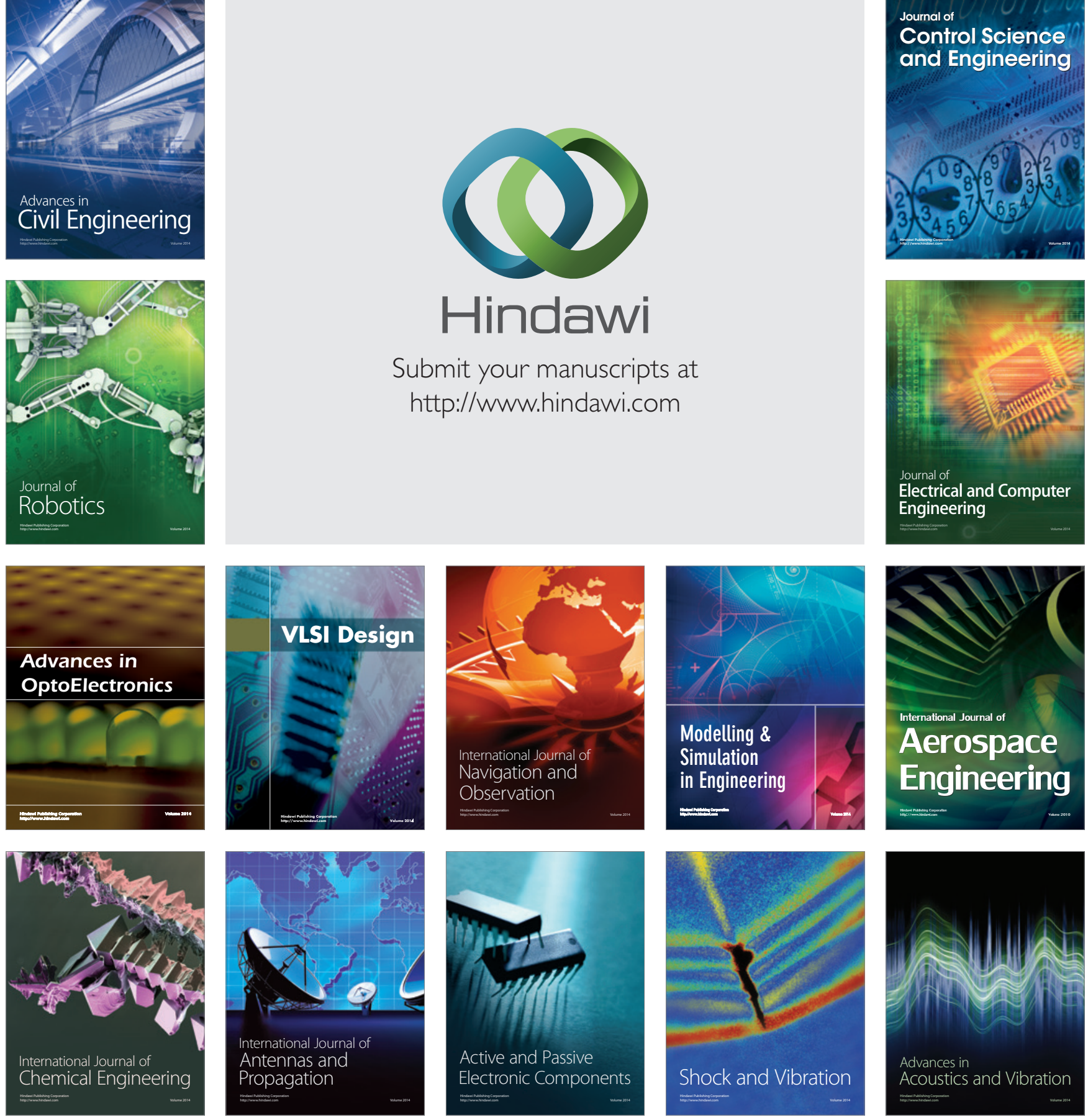